\title{
Isolation of a Constitutive $N$-Acetylneuraminate Lyase-producing Mutant of Escherichia coli and Its Use for NPL Production
}

\author{
Yasuhiro Ohta, Yoji Tsukada, Tsunetake Sugimori, \\ Kousaku Murata* and Akira KimURA* \\ Kyoto Research Laboratories, Marukin Shovu Co., Ltd. \\ Kyoto 611, Japan \\ * Research Institute for Food Science, Kyoto University, \\ Kyoto 611, Japan
}

Received September 12, 1988

\begin{abstract}
An $E$. coli mutant (M8328) was isolated by NTG mutagenesis from $E$. coli KMS3207 which has an inducible $N$-acetylneuraminate lyase (NPL). The mutant was resistant to catabolite repression and produced NPL constitutively. To improve the productivity of NPL, a hybrid plasmid, pMK6, carrying the $n p l$ gene was introduced into the mutant, M8328. The NPL activity level was increased more than 5-fold in the pMK6-harboring mutant compared with that in the mutant, when the cells were grown in inducer ( $N$-acetylneuraminic acid)-free medium. The NPLs produced by the mutant and the pMK6harboring cells were structurally and immunologically identical with that purified from the parent strain (KMS3207).
\end{abstract}

$N$-Acetylneuraminate lyase (NPL) [EC 4.1.3.3] converts $N$-acetylneuraminic acid (NANA) to pyruvate and $N$-acetyl-D-mannosamine. The enzyme is distributed in a wide variety of bacteria belonging to genera such as Escherichia, Pseudomonas, Enterobacter, Proteus, Micrococcus, Sarcina, Brevibacterium, Corynebacterium, Arthrobacter, Bacillus, Hafnia, Vibrio and Clostridium. ${ }^{13)}$ NPL is the key enzyme for the diagnostic assaying of NANA in serum or urine, ${ }^{4,5)}$ and efficient production methods for NPL have been sought by the present authors, ${ }^{6,7)}$ Kawakami et al. ${ }^{8}$ and Aisaka et al.,9) independently.

As reported previously, ${ }^{6}$ NPL is an inducible enzyme in $E$. coli and is formed only in the presence of an inducer (NANA). However, the use of NANA is limited because of its high cost. To overcome this disadvantage, we attempted to obtain an $E$. coli mutant capable of producing NPL in the absence of an inducer.

In this paper, we report the construction of a mutant that produces NPL constitutively and the production of NPL by the mutant and/or the mutant transformed with pMK6 carrying the $n p l$ gene.

\section{Materials and Methods}

Microorganisms and cultivation. Escherichia coli KMS3207, an NPL-producing strain, was used as the parent strain. E. coli cells were grown on nutrient broth (yeast extract $1 \%$, meat extract $1 \%, \mathrm{pH} 7.2$ ), L broth (peptone $1 \%$, yeast extract $0.5 \%, \mathrm{NaCl} 0.5 \%, \mathrm{pH} 7.2$ ) or minimal medium (carbon source $0.2 \%, \mathrm{~K}_{2} \mathrm{HPO}_{4} 0.7 \%$, $\left.\mathrm{KH}_{2} \mathrm{PO}_{4} 0.2 \%,\left(\mathrm{KH}_{4}\right)_{2} \mathrm{SO}_{4} 0.1 \%, \mathrm{MgSO}_{4} \cdot 7 \mathrm{H}_{2} \mathrm{O} 0.01 \%\right)$. YS medium (yeast extract $2 \%$, succinic acid $1 \%$, pH 7.0 ) was also used for assaying NPL production. Cultivation was carried out at $30^{\circ} \mathrm{C}$ with reciprocation unless otherwise noted.

Mutagenesis and selection. Mutagenesis was performed with $N$-methyl- $N$ 'nitro- $N$-nitrosoguanidine (NTG) according to the method of Adelberg et al. ${ }^{10}$ Cells in the early log phase in nutrient broth were harvested and then resuspended in a saline solution $\left(10^{8}\right.$ cells $\left./ \mathrm{ml}\right)$, followed by treatment with NTG $(100 \mu \mathrm{g} / \mathrm{ml})$ at $37^{\circ} \mathrm{C}$ for $30 \mathrm{~min}$. The mutagenized cells were collected, washed with saline and then suspended in glucose minimal medium $\left(10^{8}\right.$ cells $\left./ \mathrm{ml}\right)$.

Abbreviations: NPL, $N$-acetylneuraminate lyase; NANA, $N$-acetylneuraminic acid. 
The cell suspension was incubated for about $3 \mathrm{hr}$ and then transferred to NANA-containing minimal medium, followed by incubation for about $3 \mathrm{hr}$. This process was repeated three times. The treated cells were spread on glucose minimal agar plates to form colonies. About 100 colonies were randomly picked up and the NPL activities of the mutant cells were determined. The mutant showing the highest activity was chosen and designated as M8328.

Assay for NPL. After cultivation for $10 \mathrm{hr}$ at $30^{\circ} \mathrm{C}$, the cells were harvested by centrifugation at $15,000 \times g$ for $10 \mathrm{~min}$, washed twice with a $0.85 \%$ saline solution and then resuspended in $20 \mathrm{~mm}$ potassium phosphate buffer (pH 7.3). The cells were disrupted ultrasonically at $20 \mathrm{kHz}$ and $0^{\circ} \mathrm{C}$ for $2 \mathrm{~min}$, and then the homogenate was centrifuged at $20,000 \times g$ for $10 \mathrm{~min}$. The cell extract thus obtained was used for assaying NPL. The detailed conditions for the preparation of cell extracts and the NPL activity assay were given in our previous paper. ${ }^{11)}$ One unit of NPL activity is defined as the amount releasing $1 \mu \mathrm{mol}$ of $\mathrm{N}$-acetyl-D-mannosamine per min at $37^{\circ} \mathrm{C}$. Protein was determined by the method of Lowry et al. ${ }^{12}$

Transformation and selection. Transformation of $E$. coli M8328 was carried out as described by Norgard et al. ${ }^{13}$ ) Transformants were selected on agar plates of L-broth containing $10 \mu \mathrm{g} / \mathrm{ml}$ of ampicillin.

Purification of NPL: NPL was purified from mutant M8328 and pMK6-transformed cells, respectively. The purification method was essentially the same as that described by Uchida et al. ${ }^{11)}$

Electrophoresis. Sodium dodecyl sulphate (SDS) poly- acrylamide gel electrophoresis was performed with a separating gel of $12 \%$ acrylamide according to the method of Laemmli. ${ }^{14)}$

Immunological test. Anti-serum against the $E$. coli NPL was obtained from a rabbit immunized against purified NPL with complete Freund's adjuvant (Wako Pure Chem., Osaka, Japan). The immuno-double diffusion test was performed in $1 \%$ agarose containing $50 \mathrm{~mm}$ sodium phosphate buffer (pH 7.0).

\section{Results and Discussion}

\section{Induction and selection of an NPL constitutive mutant}

When $E$. coli KMS3207 cells were grown on the minimal medium containing NANA $(0.2$ $\%$ ) as a sole source of carbon, NPL formation was induced, the maximum being reached at the early stationary phase, and then the level remained constant throughout the culture (Fig. 1a). However, when glucose was added to the medium together with NANA, the formation of NPL was significantly repressed, although the growth of E. coli KMS3207 was not inhibited (Fig. 1b). The NPL formation increased in parallel with the decrease in glucose concentration, but the level of NPL activity was only one-third of that in the case of the NANA-minimal medium (Fig. 1a). This

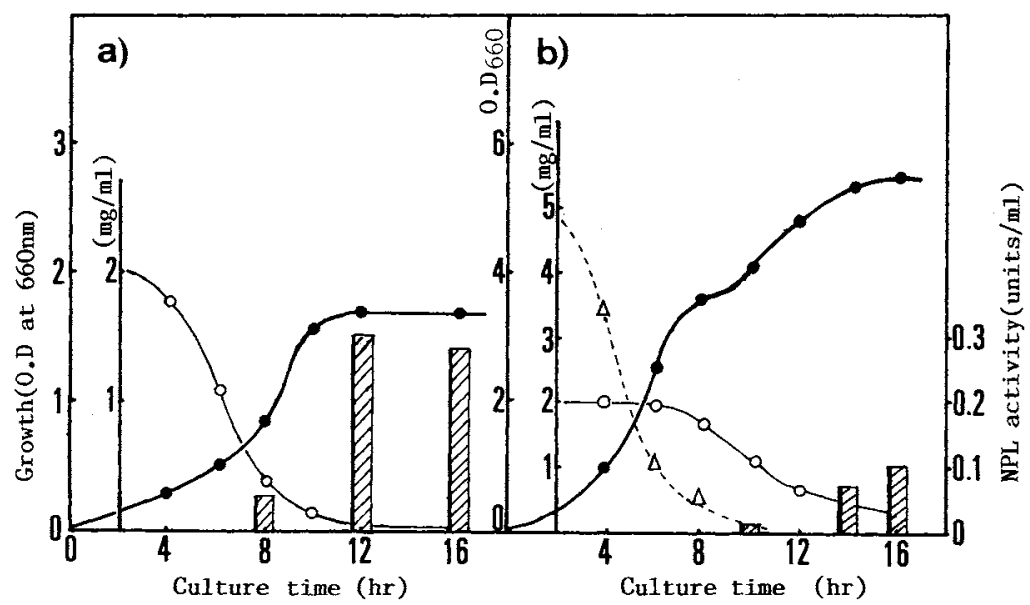

Fig. 1. Effect of Glucose on NPL Production by E. coli KMS3207.

Cells were incubated at $30^{\circ} \mathrm{C}$ in $100 \mathrm{ml}$ of the minimal medium containing NANA $0.2 \%$ (a) or NANA $0.2 \%$ and glucose $0.5 \%$ (b).

- cell growth; $\bigcirc-O$, NANA; $\triangle \cdots \Delta$, glucose; $\square \longrightarrow$, NPL activity. 
Table I. NPL Activity of Mutant M8328

The activity was determined using cell extracts as described under Materials and Methods.

\begin{tabular}{lcc}
\hline \multirow{2}{*}{ Media } & \multicolumn{2}{c}{ Strains } \\
\cline { 2 - 3 } & \multicolumn{2}{c}{ NPL activity (units/mg protein) } \\
\cline { 2 - 3 } & Wild (KM3207) & Mutant (M8328) \\
\hline NANA minimal & 0.51 & 1.27 \\
Nutrient broth & 0.00 & 1.32 \\
\hline
\end{tabular}

repressive effect of glucose on NPL formation was reversed by the addition of cyclic adenosine $3^{\prime}, 5^{\prime}$-monophosphate (data not shown), suggesting that the NPL formation is controlled by catabolite repression. If a mutant freed from catabolite repression can be obtained, it must be an NPL-constitutive strain and must produce the enzyme without an inducer. According to the procedure described under Materials and Methods, we obtained one NPL-constitutive strain, which was designated as M8328. As shown in Table I, M8328 was capable of producing NPL without NANA, demonstrating that it was an NPL-constitutive mutant. When M8328 was grown in the minimal medium containing an inducer (NANA), the NPL activity increased approximately 2fold in comparison with that of the wild strain. Furthermore, the mutant cells produced a larger amount of NPL in nutrient broth without the inducer (NANA), whereas the wild strain produced no detectable amount of NPL under the same conditions. These results indicated that the formation of NPL by mutant M8328 was insensitive to catabolite repression and that NPL could be produced irrespective of the presence or absence of an inducer (NANA).

Production of NPL by pMK6-transformed M8328

In order to further improve the productivity of NPL, hybrid plasmid pMK $6^{6,7)}$ containing the $n p l$ gene for NPL was introduced into $E$. coli M8328. The frequency of transformation of M8328 by the plasmid was approximately
Table II. NPL Activity of the Transformant

All cells were grown on YS medium and the activity was determined using cell extracts as described under Materials and Methods.

\begin{tabular}{lc} 
Strains & $\begin{array}{c}\text { NPL activity } \\
\text { (U/mg protein) }\end{array}$ \\
\hline Wild (KMS3207) & 0.0 \\
Mutant (M8328) & 1.9 \\
Transformant (M8328/pMK6) & 10.3 \\
\hline
\end{tabular}

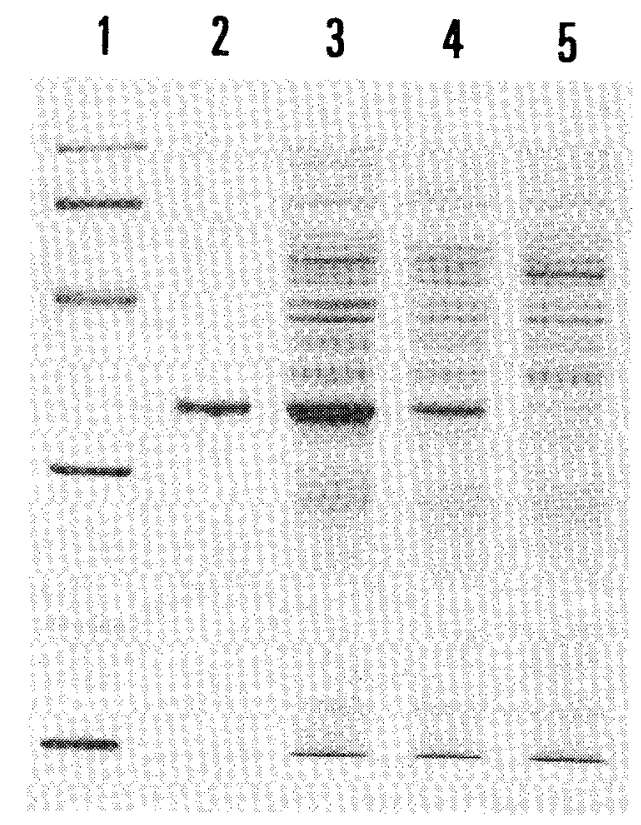

Fig. 2. Analysis of Extracts of Wild, Mutant and Transformant Cells by SDS-Polyacrylamide Gel Electrophoresis.

The conditions are given under Materials and Methods. 1, marker proteins (from top): phosphorylase $b 94 \mathrm{~K}$, bovine serum albumin $67 \mathrm{~K}$, ovalbumin $45 \mathrm{~K}$, chymotrypsinogen A $25 \mathrm{~K}$, cytochrome C $12.5 \mathrm{~K} ; 2$, purified NPL; 3, transformant (M8328/pMK6); 4, mutant (M8328); 5, wild (KMS3207).

$10^{6}$ per $\mu \mathrm{g}$ of DNA. When one of the transformants (pMK6/M8328) was grown in the YS medium, a marked increase in NPL activity (10.3 U/mg protein) was observed, as shown in Table II. Cell extracts of M8328/pMK6, M8328 and the wild strain were analyzed by sodium dodecyl sulphate polyacrylamide gel electrophoresis (SDS-PAGE) (Fig. 2). Each 
Table III. Purification of NPLs from E. coli M8328 AND M8328/pMK6

\begin{tabular}{|c|c|c|c|c|c|c|}
\hline Strains & Steps & $\begin{array}{l}\text { Total } \\
\text { units } \\
\text { (U) }\end{array}$ & $\begin{array}{l}\text { Total } \\
\text { protein } \\
\text { (mg) }\end{array}$ & $\begin{array}{l}\text { Specific } \\
\text { activity } \\
(\mathrm{U} / \mathrm{mg})\end{array}$ & $\begin{array}{l}\text { Fold } \\
\text { purification }\end{array}$ & $\begin{array}{c}\text { Activity } \\
\text { yield } \\
(\%)\end{array}$ \\
\hline \multirow{4}{*}{ M8328 } & Crude extract & 4,400 & 2,316 & 1.9 & 1.0 & 100 \\
\hline & DEAE-Cellulose & 3,564 & 125 & 28.5 & 15.0 & 81 \\
\hline & Gel filtration & 3,080 & 69 & 44.6 & 23.5 & 70 \\
\hline & Lyophilization & 2,904 & 63 & 46.1 & 24.3 & 66 \\
\hline \multirow{4}{*}{ M8328/pMK6 } & Crude extract & 22,660 & 2,200 & 10.3 & 1.0 & 100 \\
\hline & DEAE-Cellulose & 20,847 & 601 & 34.7 & 3.4 & 92 \\
\hline & Gel filtration & 19,941 & 415 & 48.1 & 4.7 & 88 \\
\hline & Lyophilization & 19,261 & 396 & 48.6 & 4.7 & 85 \\
\hline
\end{tabular}

sample gave a band corresponding to that of the purified NPL, but the intensity differed with the strain. Among these strains, M$8328 /$ pMK 6 gave the densest protein band, corresponding to a $M_{w}$ of 33,000 , a value similar to the $M_{w}$ of the NPL subunit, and the amount of NPL produced by M8328/pMK6 was calculated to comprise about $20 \%$ of the total cellular soluble protein. Thus the productivity of NPL was greatly improved by the introduction of a hybrid plasmid containing the $n p l$ gene into a mutant insensitive to catabolite repression. Since the inducer (NANA) is very expensive, the efficient and enhanced accumulation of NPL in a simple medium (YS medium) without an inducer is advantageous for the production of NPL on an industrial scale.

\section{Purification and properties of NPLs}

Typical purification procedures for NPLs from M8328/pMK6 and M8328 cells on 11 culture of broth scale are summarized in Table III. The NPLs of M8328/pMK6 and M8328 were purified approximately $4.7-$ and 24.3 -fold, and the activity yields were $85 \%$ and $66 \%$, respectively. The purified NPLs from these strains were found to be homogeneous on polyacrylamide gel electrophoresis and showed the same mobility as that purified from the wild strain (KMS3207) (data not shown). Although the detailed physicochemical properties are not shown, the NPLs purified from the two strains were the same as that in the wild strain

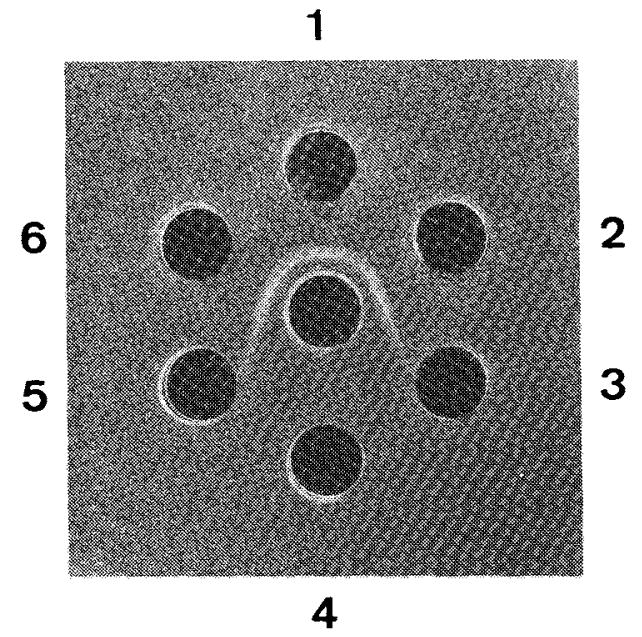

Fig. 3. Double Diffusion Test of the Purified NPLs.

Center well, anti-serum against NPL of $E$. coli $\mathrm{KMS} 3207$; Well 1, NPL from E. coli KMS3207; Well 2, NPL from the mutant (M8328); Wells 3 and 5, $20 \mathrm{~mm}$ phosphate buffer ( $\mathrm{pH} 7.3$ ); Well 4, NPL from Arthrobacter ureafaciens; Well 6, NPL from the transformant (M8328/pMK6).

with respect to the optimum $\mathrm{pH}(7.5 \sim 8.0), \mathrm{pH}$ stability $(6.0 \sim 9.0)$, temperature stability (up to $\left.65^{\circ} \mathrm{C}\right), \mathrm{Km}$ value $(3.6 \mathrm{~mm}$ for NANA) and behaviour toward inhibitors $\left(\mathrm{Ag}^{+}\right.$and $\left.\mathrm{Hg}^{++}\right)$.

Double diffusion tests were also carried out to determine the immunochemical characteristics of NPLs produced by M8328/pMK6 and M8328 (Fig. 3). The precipitin lines formed by the M8328 and M8328/pMK6 NPLs completely fused with that of the parent, indicating that the NPLs have the same immunochemical properties. 


\section{References}

1) R. B. Himer and K. Meyer, Proc. Natl. Acad. Sci. U.S.A., 42, 728 (1956).

2) E. A. Popenoe and R. M. Drew, J. Biol. Chem., 228, 673 (1957).

3) Y. Uchida, Y. Tsukada and T. Sugimori, $J$. Biochem., 96, 507 (1984).

4) K. Taniuchi, Y. Miyamoto, Y. Uchida, K. Chifu, M. Mukai, N. Yamaguchi, Y. Tsukada, T. Sugimori, K. Doi and S. Baba, Jpn. J. Clin. Chem., 7, 403 (1979).

5) K. Sugahara, K. Sugimoto, O. Nomura and T. Usui, Clin. Chim. Acta, 108, 493 (1980).

6) Y. Ohta, M. Shimosaka, K. Murata, Y. Tsukada and A. Kimura, Appl. Microbiol. Biotechnol., 24, 386 (1986).
7) Y. Ohta, K. Watanabe and A. Kimura, Nucl. Acids Res., 13, 8843 (1985).

8) B. Kawakami, T. Kudo, Y. Narahashi and K. Horikoshi, J. Bacteriol, 167, 404 (1986).

9) K. Aisaka and T. Uwajima, Appl. Environ. Microbiol., 51, 562 (1986).

10) E. A. Adelberg, M. Mande and G. C. C. Chen, Biochem. Biophys. Res. Commun., 18, 788 (1965).

11) Y. Uchida, Y. Tsukada and T. Sugimori, Agric. Biol. Chem., 49, 181 (1985).

12) O. H. Lowry, N. J. Rosebrough, A. L. Farr and R. J. Randall, J. Biol. Chem., 193, 265 (1951).

13) M. V. Norgard, K. Keen and J. J. Monakan, Gene, 3, 279 (1978).

14) U. K. Laemmli, Nature, 227, 680 (1970). 